Cadernos de Clio, Curitiba, n. ${ }^{\circ}$ 4, 2013

\title{
QUESTÕES PARA O PATRIMÔNIO CULTURAL E INTANGÍVEL NA CIDADE DE SÃO PAULO: O CASO DO CINE BELAS ARTES
}

Pedro Beresin Schleder Ferreira ${ }^{1}$

Resumo: No início de 2011 o Cine Belas Artes, tradicional sala exibidora do chamado "cinema de arte” desde 1967, recebeu ameaça de fechamento. Parte da sociedade civil realizou diversas manifestações contra o fechamento do cinema, que tiveram como plano de ação o pedido de seu tombamento. $\mathrm{O}$ artigo propõe uma investigação tanto do valor do Cine Belas Artes como bem culturais da cidade, como da possibilidade de sua inclusão no acervo do Patrimônio Cultural de São Paulo, adentrando em debates referentes à prática patrimonial no ambiente urbano que o caso em questão suscita.

Palavras-chave: patrimônio cultural urbano, patrimônio imaterial, cinemas de rua.

\section{Introdução}

“Ninguém sabe melhor que tu, sábio Kublai, que nunca se deve confundir a cidade com o discurso que a descreve. No entanto, há uma relação entre ambos."

Ítalo Calvino, “As cidades invisíveis”.

\footnotetext{
${ }^{1}$ Pedro Beresin é aluno do curso de Arquitetura e Urbanismo da Escola da Cidade, São Paulo. O presente artigo foi redigido a partir da pesquisa de Iniciação Científica desenvolvida naquela faculdade em 2011, com bolsa do Núcleo de Pesquisa daquela instituição, sob orientação da Profa. Dra. Fernanda Mendonça Pitta.
} 
Em As cidades invisíveis, do escritor italiano Ítalo Calvino, Marco Pólo narra ao imperador Kublai Kahn a diversidade e vitalidade do urbano, observadas ao longo de suas campanhas pelo mundo. As andanças de Pólo, fragmentadas em diversos núcleos circunscritos ao Império, talvez sejam, entretanto, fruto de uma única expedição a uma única cidade. À maneira de um cientista, é possível que Pólo tenha dissecado esta cidade e revelada a Kahn apenas suas diversas camadas. Boa parte das cidades narradas tem suas principais características fundamentadas no intricado entre a materialidade e a realidade psicossocial. É o caso de Irene, cidade dividida entre a parte de cima e a de baixo, distintas pelo olhar de seus habitantes que perambulam pelas ruas mirando o céu ou as calçadas (CALVINO, 1993).

As cidades, ou as ordens da cidade, são-nos reveladas pela voz e vontade do experiente navegante. Este alerta o imperador que "não se deve confundir a cidade com o discurso que a descreve”. Porém faz a ressalva: "no entanto, há uma relação entre ambos” (CALVINO, 1990, 59). O discurso sobre a cidade e sua vivência são filtrados pela subjetividade, portanto distintos do objeto a que se referem. No entanto, a experiência urbana é construída e dirigida por estas mesmas vivências e discursos. A mensagem de Pólo parece nos alertar quanto à aparência universal ou científica que os discursos costumam vestir-se, porém, distanciados desses artifícios, devemos reconhecê-los enquanto parte dialética, e não totalizante, da “realidade”. Realidade com aspas, pois nunca capturada por completo, sempre esquiva, em processo. Uma infinda sequência de totalidades que se justapõem e disputam a produção do espaço urbano. 
Nossa trajetória de análise do caso Cine Belas Artes perpassa diversas camadas de compreensão do objeto, semelhantes às observadas nas expedições de Pólo. Foi preciso atacá-lo por diversos lados e utilizar diversos instrumentos a fim de lapidá-lo. Finalmente extraímos nossa questão fundamental: a valoração simbólica e afetiva no meio ambiente urbano e o desenvolvimento do pensar e construir a cidade a partir dessa camada da existência social.

Percebemos que dois grandes temas orbitavam o objeto. Eles mereceram análises distintas no decorrer do trabalho: as questões patrimoniais e a valoração social. Nossa opção foi analisá-los separadamente e buscar suas confluências ao final da pesquisa.

Julgamos que um dos principais conflitos presentes na questão da preservação do Cine Belas Artes está na simultânea inter-relação de seus aspectos, definidos pela teoria do Patrimônio Cultural (Chagas 2002; Fonseca, 1997), de valor material e imaterial. Dessa maneira a presente pesquisa visa aprofundar a compreensão do valor sociocultural do caso específico do Cine Belas Artes a fim de subsidiar discussões acerca de sua preservação e cooperar para o debate de maior amplitude sobre os critérios de atribuição de valor predominantes e novas formas de atuação para a preservação e conservação do Patrimônio Cultural no meio ambiente urbano.

A respeito das valorações materiais e imateriais presentes no caso em questão, procuramos compreender a relação do Cine Belas Artes com a vida na metrópole, através do fenômeno de territorialização (Carlos apud Veiga, 2005), ou seja, de demarcação social do território e constru- 
Cadernos de Clio, Curitiba, n. ${ }^{\circ}$ 4, 2013

ção de significados e valores ${ }^{2}$, tanto em seus aspectos objetivo quanto subjetivo.

Ao primeiro aspecto concerne a análise do Cine Belas Artes como equipamento cultural da cidade, relevante na difusão de uma cultura cinematográfica específica e, junto com outros cinemas de rua, engendrador de uma mancha cultural (Magnani, 1987) importante para a vida de determinados grupos sociais em São Paulo. A fim de compreendê-lo, recorremos a estudos anteriores sobre o circuito de cinemas de rua da Av. Paulista (Stefani, 2003; Torres, 1996; Almeida, 1996) e às entrevistas com frequentadores do Cine Belas Artes realizadas por Fábio Ornelas (2011). Como bibliografia complementar, utilizamos autores que tratam da trajetória de desenvolvimento das centralidades culturais em São Paulo, como Frúgoli, 2000 e Santoro, 2004.

Quanto à análise subjetiva, valemo-nos de entrevistas por nós realizadas com integrantes do MBA (Movimento pelo Cine Belas Artes) e de entrevistas realizadas por Torres, 1996 e Ornelas, 2011. Como bibliografia complementar, utilizamos pensadores que tratam da relação de construção do significado e da identidade no espaço, como Meneses, 2006; Hall, 2006; Veiga, 2005; Magnani, 1987; e Arantes, 2006, entre outros.

É importante ressaltar que durante o processo de pesquisa, o autor envolveu-se diretamente em ações e discussões acerca da preservação do Cine Belas Artes ocorridas em São Paulo. Dessa maneira, para além da voz captada através das entrevistas, destaca-se como importante dado para a pesquisa a própria experiência do autor e sua vivência da cidade. As

\footnotetext{
${ }^{2}$ Adotamos o entendimento de que os valores culturais não imanam das coisas, mas são construções sociais (MENESES, 2006; ARANTES, 2006).
} 
entrevistas, portanto, não se articulam enquanto dados quantitativos, mas primordialmente qualitativos e muitas vezes se aproximam dos posicionamentos do próprio autor.

\section{Questões Patrimoniais}

Antes de penetrar no embate com as problemáticas patrimoniais sugeridas pelo caso do Cine Belas Artes, se faz necessário o despir de certos conceitos, enrijecidos ao longo do tempo, associadas à disciplina. Tentaremos, para isso, desnaturalizar a noção de Patrimônio Cultural (Chagas, 2002), acompanhando algumas reflexões realizadas dentro desse campo teórico.

A primeira é a noção de perenidade, unicidade e universalidade atribuída à disciplina patrimonial e objetos tombados, que se aproximam da sacralidade de um museu (casa de memória e poder) à qual também se soma o valor da antiguidade per se (Chagas, 2002). Em oposição à essa adotamos a noção de que o Patrimônio Cultura é fruto da articulação de discursos, como todo fato social, sendo um construto cultural, portanto sujeito à transformação e à crítica assim como toda e qualquer forma de organização humana:

“[...] As considerações dos excluídos, das singularidades e o silêncio na atual escrita da História, é um fator que, juntamente com a percepção do patrimônio como fator cultural, tende a modificar este quadro, pois desvenda o existir não apenas de um patrimônio, mas de patrimônios, cada um dos quais referenciados em memórias específicas ou locais cujo valor tem que ser aferido por critérios múltiplos.” (grifo nosso) (Rodrigues, 1996: 13). 
Qualquer coisa ou fenômeno do mundo é passível de valor patrimonial e de preservação, que são categorias e etapas distintas da disciplina. Dessa maneira temos um Patrimônio não só de categorias móveis, mas também dinâmico, pois parte das transformações sociais. A distinção que Halbwachs (1990) faz dos conceitos de História e Memória nos parece análoga às duas formas de patrimônio a que estamos nos referindo, conforme recuperadas por Nora (1993):

“A história é reconstrução sempre problemática e incompleta do que não existe mais. A memória é um fenômeno sempre atual, um elo vivido no eterno presente; a história, uma representação do passado. (...) A memória emerge de um grupo que ela une o que quer dizer, como Halbwachs o fez, que há tantas memórias quantos grupos existem; que ela é, por natureza, múltipla e desacelerada, coletiva, plural e individualizada. A história, ao contrário, pertence a todos e a ninguém, o que lhe dá uma vocação para o universal. A memória se enraíza no concreto, no espaço, no gesto, na imagem, no objeto. A história só se liga às continuidades temporais, às evoluções e às relações das coisas. A memória é um absoluto e a história só conhece o relativo" (Nora, 1993: 09).

Este trecho nos conduz à outra face da prática patrimonial que nos interessa: a prática do patrimônio como projeto social. Uma acepção da disciplina que leve em conta as duas dimensões colocadas por Nora. Seguindo Antônio Arantes (2006), encontramos no patrimônio a potência de um discurso transformador:

"A temática do patrimônio quando associada, ao mesmo tempo, às noções de memória e futuro sugere não só uma relação entre memória social e projeto social, isto é, entre a memória social e a construção no presente das perspectivas futuras de uma formação sócio-territorial; sugere também que, de alguma forma, o patrimô- 


\section{Cadernos de Clio, Curitiba, n. ${ }^{\circ}$ 4, 2013}

nio histórico-cultural participa desta relação, da memória social com a construção das soluções dos problemas com os quais se confronta uma sociedade" (Arantes, 2006: 3).

O patrimônio para além de instrumento museográfico para a preservação da cultura erudita, constrói através da rememoração e da vivência as bases para um projeto social. Decide pela lembrança ou o esquecimento, que serão os possíveis pilares de sustentação para memórias transformadoras (Nora, 1993). Eis a importância da história vista a contrapelo assinalada por Benjamin (apud Rouanet, 1987), pois a permanência das derrotas marca a permanência dos conflitos, enquanto o esquecimento tenderá a apagá-los. Uma das possíveis compreensões do fenômeno social de busca pela salvaguarda do Cine Belas Artes tange essa leitura, entendendo o cinema em questão como um espaço de resistência. Dessa maneira a disciplina patrimonial torna-se indissociável do Urbanismo e passa a ser compreendida como uma prática política.

A outra noção a ser deslocada diz respeito às categorias da materialidade e imaterialidade de um bem patrimonial. A cultura, em última instância, é um amálgama de símbolos, ritos e práticas, com diferentes formas de manifestação. A materialidade e a imaterialidade de uma cultura são duas faces indissociáveis de uma mesma moeda. Esta interdependência é raramente exaltada em casos de tombamento, embora muitas vezes seja contemplada, como no caso do Teatro Oficina e do Mercado Municipal de São Paulo, tombados pelo valor material (seguindo os tradicionais critérios da valoração arquitetônica), mas que tiveram usos sugeridos pelo órgão municipal (Conpresp) e estadual (Condephaat) responsáveis pela preservação do Patrimônio Cultural em São Paulo, usos estes que susten- 
tam não só lugares e vivências na cidade, mas também sua memória coletiva. Dessa maneira, o discurso patrimonial expande-se do âmbito técnico para os diversos valores estabelecidos por outros grupos sociais.

Como definido por Argan (1992), o tratamento da cidade deve darse em duas vias: a função e o espaço visual, aquele trabalhado também por Lynch (2011), cuja origem é a imagem da cidade construída na interioridade de seus habitantes. Para Argan um lugar da cidade deve ser objeto de tratamento do urbanismo quando, como se fossem sobrepostos os mapas afetivos de todos os habitantes, este formar pontos de concentração afetiva, constituindo um lugar que transcende a vivencia individual e passa a ser um lugar social. Essa observação equivale ao direito à memória e à cidade, apontados nas reivindicações sócias observadas no caso em questão ${ }^{3}$.

No caso do Cine Belas Artes, devido a uma suposta ausência de valor material de caráter técnico arquitetônico ${ }^{4}$, a contradição vem à tona. Comporta memória social e constitui importante lugar para a vida da cidade. O edifício aqui é valorado enquanto recipiente. Há grande recusa

${ }^{3}$ Em entrevista realizada por nós, Jorge Rubies, ex-usuário do Cine Belas Artes, declara: "Mas de qualquer forma, o movimento em defesa do Cine Belas Artes é emblemático: hoje em dia, a cidade está nas mãos da especulação imobiliária - a preservação e a reabertura do Belas Artes significará uma vitória da cultura, da arte e de todos os valores humanos mais elevados sobre a ganância, a cobiça e esse poder brutal da especulação imobiliária.“(Jorge, 45 anos)

${ }^{4}$ Segundo Fonseca, é notório que a prática dominante de ações de preservação de bens materiais no Brasil permanece pautada pelos valores de excepcionalidade das obras no que se refere ao seu valor artístico ou arquitetônico (FONSECA, 1997). 
entre os técnicos na utilização do Instituto do Tombamento ${ }^{5}$ nesses casos, afirmando a restrita abrangência a objetos de valor artístico e excepcional da cultura brasileira, mais especificamente, a bens arquitetônicos e obras de arte. Surge a questão: deve-se abranger a atuação do instituto do tombamento ou criar novas ferramentas ${ }^{6}$ ?

O terceiro ponto a ser tratado acerca dos deslocamentos das noções do Patrimônio Cultural diz respeito aos limites da disciplina. Os órgãos de preservação do Patrimônio Cultural são agentes de produção do espaço urbano. Sua atuação, portanto é política (Arantes, 2006), e está estritamente ligada aos anseios da sociedade enquanto coletividade:

“A orientação e eficácia do trabalho com o patrimônio cultural dependem, visceralmente, de nosso projeto de sociedade, do tipo de

5 Regido no Estado de São Paulo pelo Decreto Estadual $\mathrm{n}^{\circ}$ 13.426, de 16/mar/1979, pautado no DL n ${ }^{\circ}$ 25/37.

${ }^{6}$ Um exemplo elucidativo dessa questão é o registro da Cachoeira do Iauaretê (AM), realizado pelo IPHAN em 2006. O valor reconhecido pelo IPHAN nesse local remete-se ao valor espiritual e mítico atribuído pelas tribos indígenas que vivem às redondezas da cachoeira. Nesse caso, a opção pelo Registro é coerente por não enrijecer o valor daquele espaço, pois se tratando de uma valoração de ordem espiritual e mítica, está sujeito á mudanças ao longo do tempo. Dessa maneira, o bem valorado é preservado através da chancela do IPHAN e mantém as atribuições materiais e imateriais do bem distintas para futura manutenção. Porém, no caso de uma disputa por essa propriedade, como ocorre comumente em meios ambientes urbanos como o de São Paulo, o Registro demonstra-se pouco eficiente para a garantia dos valores culturais preservados, pois não propicia o cerceamento de propriedade à maneira do instituto do tombamento. No caso do Cine Belas Artes, seriam necessárias para a preservação as qualidades de ambos os instrumentos, porém, da maneira como estão instituídos e regulamentados é impossível, uma vez que contraditórios no que se refere à qualidade e temporalidade do valor que cada instrumento contempla. 
Cadernos de Clio, Curitiba, n. ${ }^{\circ}$ 4, 2013

relações que desejamos instaurar entre os homens” (Meneses 1992: 194 apud Arantes, 2006).

Toda prática preservacionista está articulada com algum projeto de sociedade e cidade. No caso estudado, foi de ampla discussão se haveria pertinência na utilização do rígido instituto do tombamento para a salvaguarda do Belas Artes, como explicitado por Silvio Oksman (2011) em seu artigo “Patrimônio: Panaceia?”.

Pode-se pensar o Tombamento do Cine Belas Artes sob duas matrizes: o uso político do Tombamento e/ou da transformação das políticas patrimoniais e deu seu “projeto de sociedade”. Pela primeira poderíamos pensar que mesmo não garantindo as qualidades requisitadas pela sociedade para o bem em questão, a utilização do tombamento traria poder à sociedade civil, daria validade ao seu desejo:

“Se a memória social depende da narração para sua continuidade, a paisagem urbana também poderia contribuir a partir da memória do lugar que seria, para o filósofo (Aristóteles), a presença estabilizadora do lugar como um contendor de experiências que contribui tão poderosamente para a sua memorabilidade (sic) intrínseca” (Castriota, 2009: 124).

O tombamento poderia ser entendido como um gesto político, que percebe o processo de preservação de maneira mais complexa, em longo prazo. No caso do Cine Belas Artes, possibilitaria à sociedade civil mobilizada realizar a articulação faltante entre o órgão patrimonial municipal (Conpresp) e as secretarias responsáveis pelo planejamento da cidade, ou que se formem estratégias extraoficiais para a preservação do Patrimônio 
Cultural (à maneira da preservação realizada em 2004, que analisaremos mais adiante).

Dentre os órgãos públicos atuantes na cidade de São Paulo, talvez os responsáveis pelo Patrimônio Cultural (Conpresp e Condephaat) sejam os únicos onde é possível que qualquer cidadão abra um processo sem grandes barreiras burocráticas. Essa a nossa hipótese para o fato de casos, como o de nosso estudo, acabarem sendo direcionados aos órgãos patrimoniais e terem seu debate circunscrito a esse campo.

As questões de preservação, dizem respeito aos referidos órgãos públicos, porém esse tipo de ação não é específico a esses, havendo diversas possibilidades para que seja efetuado por outros segmentos do Estado que comportam instrumentos eficientes como a desapropriação, as PPP's (Parceria Público- Privado) e a elaboração e gestão dos Planos Diretores Estratégicos ${ }^{7}$. Por outro lado, essas políticas estão mais afastadas do cidadão comum, e normalmente comprometidas com agendas políticas préestabelecidas para as Secretárias Municipais.

${ }^{7}$ Pode-se utilizar como exemplo o Plano Diretor Estratégico de São Paulo (Lei Municipal $\mathrm{N}^{\circ}$ 13.430/2002), que determina as ZEPECs ( Zonas Especiais de Preservação Cultural), que determinam regulamentação específica para determinados trechos urbanos, garantindo uma gestão mais apurada de áreas e bens com valor cultural atribuído pela sociedade de maneira mais flexível que o Instituto do Tombamento e sem a necessidade de onerar o Poder Público, como ocorre na desapropriação. A definição das ZEPECs também viabilizam a utilização de outros instrumentos previstos no PDE de São Paulo, que podem cooperar na negociação entre os interesses públicos e privado sobre a propriedade como o direito de preempção, a permuta de terrenos e a transferência de potencial construtivo. §No que tange às PPP's, a mitigação de impostos via Lei Rouanet (PROAC e PRONAC), tem grande potencial para a preservação de bens culturais, como já foi realizado no próprio Cine Belas Artes, que foi patrocinado pelo HSBC de 2004 até 2010. 


\section{Cadernos de Clio, Curitiba, n. ${ }^{\circ}$ 4, 2013}

Gostaríamos de sugerir uma reflexão sobre a questão sob o prisma da manutenção do cotidiano citadino. Agir sobre o bem de forma diversa à que se tem feito com os vários bens tombados que permanecem alienados de uso ou que tem para sua inserção no meio urbano a solução genérica de centros culturais, muitas vezes incompatíveis com o entorno. Retomemos os exemplos do Teatro Oficina e do Mercado Central. A importância de seus usos para a preservação e vivência do bem com certeza se equipara à preservação material. Proteger o uso (e isso não significa tombá-lo, pois há outras maneiras para fazê-lo, como colocado a pouco) é garantir a manutenção de uma atividade de produção cultural e de um espaço identitário e constituinte de um grupo social da cidade.

A recuperação do Cine Belas Artes em $2004^{8}$, realizada pela produtora $\mathrm{O} 2$ Filmes junto à distribuidora Pandora Filmes, pode ser significada como uma ação de preservação material e imaterial do cinema independente dos instrumentos oficiais. O edifício então se encontrava em condições materiais inviáveis para desenvolver sua atividade. A reforma do edifício, realizada por Roberto Loeb, agiu sobre o material de acordo com sua valoração imaterial, ou seja, a nosso ver, não consiste em um processo de restauro arquitetônico, mas de restauro de uso, de urbanidade. Dessa forma o arquiteto sentiu-se livre para criar novos espaços de convivência (como o hall do segundo andar, a abertura para a Rua da Consolação e a lanchonete no térreo) assim como reconfigurar livremente as salas de exibição. Apesar da intervenção na fachada, a linguagem do modernismo quase purista de Palanti, foi respeitada (Sanches, 2011), apontando para o

\footnotetext{
${ }^{8}$ O Estado de São Paulo. Caderno 2, publicado no dia 5 de abril de 2004.
} 
respeito também ao valor erudito e histórico do bem. Note-se que essa ação conseguiu equilibrar o interesse financeiro e mercadológico dos entes envolvidos com a interpretação e respeito ao valor social atribuído para aquele espaço.

A ideia dessa recuperação era revitalizar aquele lugar tão caro à cidade de São Paulo. Por isso foi imprescindível a associação de Fernando Meirelles e André Sturmn na direção das atividades do cinema. A recuperação tanto do caráter de programação que o cinema havia desenvolvido até os anos 90, assim como de suas atividades de teor cultural, garantiram, junto à recuperação das instalações, que aquele voltasse a ser um lugar da cidade. As movimentações ocorridas no começo de 2011, reunindo desde jovens até idosos, são a prova da eficiência desta ação de preservação, verdadeiramente efetiva não só na preservação da memória, mas também da vida na cidade, contemplando as duas esferas de valor que aqui lidamos: a memorial e a manutenção do lugar.

\section{O lugar de cinema}

Antes de iniciar a análise que prossegue cabe uma salvaguarda. Procuramos ao máximo nos esquivar de sentimentalismo e de julgamentos de valor. Não queremos provar o valor do Cine Belas Artes, que parece já bastante assentado, mas compreender os motivos que levaram seu caso a tal ponto de manifestação. Quais motivos levaram centenas de paulistanos a sair nas ruas, realizar passeatas, lotar o cinema em seu último mês de funcionamento, preencher extensas listas de abaixo assinado, e ainda organizar um movimento social organizado específico para o caso? 
Grande parte da problemática desenrolada pelo caso do Cine Belas Artes diz respeito à decisão de que modelo e instrumentos seriam adequados à sua preservação. A dificuldade está concentrada, dentre outras, na ideia de preservação do uso. O uso, tradicionalmente no Urbanismo é tratado de forma restrita a seu caráter utilitário e funcional. Este conceito de uso esquadrinha as experiências da cidade, reduzindo-as a seu caráter quantitativo. Entre o lazer e o trabalho, há a vida de todos habitantes da cidade. Uma sala de cinema não é nem somente funcional, nem somente lazer, mas uma experiência coletiva e individual multifacetada.

Uma cartografia afetiva do Cine Belas Artes, que perpassa o discurso proferido por seus frequentadores durante o período que concerne ao último mês de funcionamento do cinema, seria nossa proposta para aprofundar a noção do uso e, consequentemente, do lugar Belas Artes, assim como para a constituição de um instrumento coerente para sua preservação. Pensamos à maneira da psicogeografia situacionista, em que a experiência surge como dado para o conhecimento do meio urbano (Jacques, 2003).

Por esse motivo procuramos compreender a relação do Cine Belas Artes com a vida na metrópole. Pensamos no fenômeno de territorialização, ou seja, de demarcação social do território, tanto em seus aspectos objetivo quanto subjetivo. Ao primeiro concerne a análise do Cine Belas Artes como um equipamento cultural da cidade, relevante na difusão de uma cultura cinematográfica específica e, junto com outros cinemas de rua, engendrador de uma mancha cultural (Magnani, 1987) importante para a vida de determinados grupos sociais em São Paulo. 
Quanto à análise subjetiva, cremos ser necessário compreender o cinema como lugar presente na cartografia afetiva, imaginativa e cotidiana de grupos sociais da cidade, que por muito tempo apropriaram-se deste espaço e agora tratam de reivindicar sua salvaguarda.

Como introdução ao nosso universo conceitual abordamos a noção de lugar em oposição à de espaço de forma a aprofundar a relação entre sociedade e espaço físico. Segundo Ana Fani Carlos:

"Lugar é a porção do espaço apropriável para a vida (...) é o bairro, é a praça, é a rua, e nesse sentido poderíamos afirmar que não seria jamais a metrópole ou mesmo a cidade lato sensu a menos que seja a pequena vila ou cidade - vivida/conhecida/reconhecida em todos os cantos. (...) A metrópole não é 'lugar', ela só pode ser vivida parcialmente” (Carlos apud Veiga, 2005: 44).

Um espaço está cercado de outros espaços. Um lugar está cercado de significados. A existência de um lugar depende de sua apropriação por um indivíduo ou grupo. Espaços são apenas as localidades, os endereços e constituições físicas da cidade. Lugares são espaços compreendidos na vida de seus habitantes.

Dessa forma podemos dizer que existe um espaço para todos: a cidade. Porém sobre esse mapa do espaço se sobrepões milhares de outros mapas de lugares, constituídos pela afetividade do cotidiano de cada indivíduo. Cada um estabelece uma afetividade singular com a cidade e se apropria em seu cotidiano de elementos e de forma distintas do espaço. Agora imaginemos todos esses mapas da cidade sobrepostos:

"Se, por hipótese absurda, pudéssemos levantar e traduzir graficamente o sentido da cidade resultante da experiência inconsciente de 
cada habitante e depois sobrepuséssemos por transparência todos esses gráficos, obteríamos uma imagem muito semelhante à uma pintura de Jackson Pollock, por volta de 1950: uma espécie de mapa imenso, formado de linhas e pontos coloridos, um emaranhado inextricável de sinais, de traçados aparentemente arbitrários, de filamentos tortuosos, embaraçados, que mil vezes se cruzam, se interrompem, recomeçam e, depois de estranhas voltas, retornam ao ponto de onde partiram.” (Argan, 1990: 178)

Nesse mapa virtual seria possível imaginar que agregando os mais distintos trajetos há certos pontos de convergência, de adensamento. Podem dar-se por diversos motivos, podem delimitar-se de diversas formas. São esses, os lugares que transcendem a representatividade individual. O passeio da Av. Paulista e o bairro do Bexiga em São Paulo, são exemplos deste fenômeno. Magnani (1987) identifica que grande parte dessas significações urbanas está associada às práticas de lazer, pois constituem uma das grandes agregadoras da vida coletiva paulistana no espaço comum.

Veiga (2005) analisa que "o que caracteriza o lugar seria a vivência que dele se faz e o que define o homem seriam os lugares que compõem seu cotidiano”. Dessa forma entendemos que não há um caminho unívoco na determinação de espaços como lugares, mas bidirecional, onde indivíduo ou grupo dão identidade a um espaço, tornando-o lugar, ao passo que esse automaticamente passa a constituir parte da identidade desses atores. Há uma relação de ambivalência dialética entre sujeito-espaço, que vai muito além da fruição estética ou do uso. Como colocado por Carlos ( $a$ pud Veiga, 2005), um lugar não é apenas conhecido, mas local de reconhecimento, de identificação.

Para entendermos a aplicação desses conceitos no caso do Cine Belas Artes, devemos entender e identificar os grupos sociais participantes. 
Nossa hipótese inicial para a delimitação do referido grupo social, assim como colocado por Torres (1996), partiu da caracterização desse grupo como um público de consumo “intelectualizado”. Diversos depoimentos ${ }^{9}$ referem-se à qualidade e singularidade da programação deste cinema, desde seus primórdios, referida como “cinema de arte”, caracterizando-o como espaço de encontro de indivíduos que partilham um mesmo gosto.

André Pompéia Sturmn, programador do cinema até seu fechamento, em palestra proferida na Casa da Cidade no dia 17 de agosto de 2011, provavelmente alheio aos estudos até agora citados, revelou sua impressão sobre o público frequentador do cinema, identificando o que chamou de uma "cultura do Cine Belas Artes”. Conta que as pessoas iam para o Cine Belas Artes sem saber o que estava passando, pois identificavam seus gostos com a programação distinta do cinema, estabelecendo um elo de confiança e identidade bastante específicos. (Sturmn, 2011)

\section{A formação do lugar}

As reações contra o fechamento do Cine Belas Artes não nos deixam mentir. A pesquisa de Magnani (1987) referente à territorialização de São Paulo pelos diferentes grupos que constituem a cidade, é conveniente para o entendimento da relação entre as formas de sociabilidade e as delimitações do espaço urbano. Procurando entender a forma como essas relações dão-se no Centro de São Paulo, verificou que as unidades de

\footnotetext{
${ }^{9} \mathrm{O}$ referido discurso se faz presente nos depoimentos por nós recolhidos com os ex-usuários do cinema envolvidos nas movimentações sociais para sua preservação, Jorge Rubies e Afonso Junior em fevereiro de 2012, assim como nas entrevistas realizadas anteriormente por Torres (1996) e Ornelas (2011) com usuários do Cine Belas Artes.
} 
Cadernos de Clio, Curitiba, n. ${ }^{\circ}$ 4, 2013

análise eram definidas em função exclusiva de atividades de lazer e encontro, em oposição aos bairros, onde verificou-se a moradia e a vizinhança como referencias primordiais (Magnani, 1987).

Cada grupo "marca” seu território não só com sua ocupação presencial e os signos que carregam os indivíduos, mas também com "sensíveis diferenças nos estilos de apropriação e uso do espaço” (Magnani, 1987). Espaços esses que atraem o usuário tanto para uma utilidade comum, como:

“(...) para encontrar seus iguais, exercitar-se no uso dos códigos comuns, apreciar os símbolos escolhidos para marcar as diferenças. É bom estar lá, rola um papo legal, fica-se sabendo das coisas... e é assim que a rede de sociabilidade vai sendo tecida.” (Magnani, 1987:2).

Aqui os frequentadores não se conhecem, mas se reconhecem como portadores de símbolos que remetem a valores diversos, gostos, orientações etc.

Há também lugares em que o fator determinante de apropriação é exercido predominantemente pelo componente espacial em detrimento do simbólico. São locais considerados ponto de referencia para frequentadores portadores de identidades sociais diversas. O Cine Belas Artes enquanto ponto de encontro e referência da cultura cinematográfica intelectual da cidade é uma possibilidade, assim como parte de uma mancha ${ }^{10}$ maior representativa dessa mesma cultura.

${ }^{10}$ O termo mancha, precisa Magnani, designa "uma área contígua do espaço urbano dotada de equipamentos que marcam seus limites e viabilizam - cada qual 
Dessa forma podemos concluir parcialmente que parte da importância do Cine Belas Artes, manifesta em sua defesa, está diretamente relacionada com a particular atividade desenvolvida nesse espaço. Seu mote de abertura foi a criação de um circuito de programação paralela à hegemonia de Hollywood, presente em mais de $85 \%$ das salas de cinema de São Paulo (Stefani, 2007). Nos últimos anos, após a reforma, dedicou sua programação a filmes europeus e lançamentos nacionais, assim como mantinha um programa de cineclube, o tradicional Noitão, sessão extraordinária em que eram exibidos filmes ao longo da madrugada, e cursos de direção e roteiro. Além do mais era um dos grandes palcos da Mostra Internacional de Cinema, que tem nos cinemas de rua da Av. Paulista grande parte de sua atividade desenvolvida.

O circuito das salas de "cinema de arte” da Av. Paulista caracterizase como uma mancha urbana. Uma mancha que concentra $90 \%$ das poltronas destinadas à exibição do “cinema de arte” na cidade, agrupadas em seis salas localizadas no polígono formado pela Av. Paulista, Rua da Consolação e Rua Augusta. O Cine Belas Artes é um dos vértices dessa formação urbana (Stefani, 2007). Dessa forma, a nosso ver, o Cine Belas Artes possui características que transcendem uma sala de cinema, beirando, em interação com seus arredores, a configuração de um centro cultural.

O que querem os manifestantes com o pedido de salvaguarda? Querem a manutenção tanto de um espaço de identificação e ordenação afetiva do espaço urbano, como de um equipamento cultural notável no cená-

com sua especificidade, competindo ou complementando - uma atividade ou prática predominante” (Magnani, 1987:3) 
rio do lazer urbano paulista. Querem exercer seu direito duplo à cidade, como definido por Argan (1992): da função como da imagem da cidade, de seu estreito relacionamento com o espaço, de seu lugar.

A delimitação de um lugar na cidade é um fenômeno social. Encontramos na conceituação de lugar nosso principal pilar de apoio teórico. Porém os delineamentos do conceito de lugar/ territorialidade encontrados na bibliografia são demasiadamente genéricos e pouco aprofundados, como descritos anteriormente.

\section{A construção do lugar}

Segue então uma tentativa de abordagem da constituição do lugar diretamente a partir do caso estudado. Sem a pretensão de elaborar um conceito universal, através de entrevistas e consultas a depoimentos recolhidos por outros autores, procuramos compreender qual a significação atribuída por seus ex-usuários e pelo movimento organizado para a sua salvaguarda.

Nossa estratégia partiu da análise da prática discursiva, tanto plural como subjetiva. Procuramos encontrar na fala de nossos entrevistados os momentos em que o particular, individual, transita ao comum, coletivo. No conjunto o fizemos buscando as constantes discursivas enunciadas pelos entrevistados. Nos particulares procuramos compreender os momentos em que o discurso apoia-se em questões de maior amplitude do que a experiência subjetiva ou que procura reforçar a própria experiência. Assim como proposto pela Internacional Situacionista (Jacques, 2003), buscamos cartografar a ambiência psíquica do Cine Belas Artes enquanto parte da 
complexa e difusa trama dos sentidos produzidos no meio ambiente urbano.

A fim de organizar nossas hipóteses, foram distintos três filtros de análise, referentes a três hipóteses da construção do lugar Cine Belas Artes. São: a experiência do cinema, construção de identidade e ideia de cidade. As duas primeiras consideramos fundamentais para a concepção de lugar a que pretendemos esclarecer. A terceira também, porém de maneira distinta, na qual o Cine Belas Artes é feito sinédoque de um espectro de utopia urbana.

A partir dos depoimentos de ex-usuários, analisados a partir de Ornelas (2012) e de nossas entrevistas, pudemos perceber que grande parte das significações atribuídas ao cinema estão diretamente relacionadas com a experiência do cinema em si. A afetividade com a materialidade daquele espaço, daquele endereço, assim como suas memórias, compartilham estreitos laços com os filmes assistidos no local.

Por último, foi patente na análise dos discursos que para além da resolução do Caso do Cine Belas Artes e através dele, os entrevistados proferem um discursos sobre a cidade, revelando como a desejam e imaginam. É de grande valor aqui a distinção feita por Harvey (apud Haesbaert, 2011) entre espaço de representação e espaço vivido. O espaço vivido é aquele da experiência, seu discurso é restrito à esfera de locações específicas e suas relações com grupos e indivíduos. Já o espaço de representação é construído como suporte para um reflexão mais ampla da cultura, ele representa alguma coisa. O desejo de permanência do Cine Belas Artes, a 
nosso ver, representa e se relaciona com o desejo de uma radical transformação no processo de construção do ambiente urbano de São Paulo ${ }^{11}$.

\section{Bibliografia}

ARANTES, Antonio A. O patrimônio cultural e seus usos: a dimensão urbana in Habitus, Goiânia, n. 4, jan/jun 2006.

ARGAN, Giulio Carlo. História da Arte como História da Cidade. Ed. Martins Fontes, São Paulo, 1992.

CASTRIOTA, Leonardo Baci. Patrimônio Cultural: Conceitos, Políticas, Instrumentos. Ed. Annablume, São Paulo, 2009.

CALVINO, Ítalo. As cidades invisíveis. Cia das Letras, São Paulo, 1990.

CHAGAS, Mário e ABREU, Regina. Memória e Patrimônio: ensaios contemporâneos. Ed. Lamparina, Rio de Janeiro, 2002.

Entrevista com o membro do MBA (Movimento pelo Cine Belas Artes) Afonso Junior, abril, 2012.

Entrevista com o ex-usuário do Cine Belas Artes, Jorge Rubies, março, 2012.

FONSECA, Maria Cecília Londres. O patrimônio em processo: trajetória da política federal de preservação no Brasil. Ed UFRJ, Rio de Janeiro, 1997.

HALBWACHS, Maurice. A memória coletiva. São Paulo: Vértice, 1990.

JACQUES, Paola Berenstein (org.). Apologia da Deriva: escritos situacionistas sobre a cidade. Ed. Palavra, Rio de Janeiro, 2003.

KUSTER, Eliane e PECHMAN, Robert. Maldita rua. Instituto de Pesquisa, UFRJ, Rio de Janeiro, 2008.

LYNCH, Kevin. A imagem da cidade. Ed. 70, São Paulo, 2011.

MAGNANI, José Guilherme. Da Periferia ao Centro: pedaços e Trajetos. Revista de Antropologia, São Paulo, 35, 1987.

11 “Questões para o patrimônio cultural de São Paulo: o caso do Cine Belas Artes”, 2012, Relatório final de Iniciação Científica. Pode ser encontrado na biblioteca Villanova Artigas da Faculdade de Arquitetura e Urbanismo - Escola da Cidade 
MENESES, Ulpiano Toledo Bezerra de. A cidade como bem cultural - Áreas envoltórias e outros dilemas, equívocos e alcance na preservação do patrimônio ambiental urbano in Patrimônio: atualizando o debate. IPHAN, São Paulo, 2006.

NORA, Pierre. Entre Memória e História: a problemática dos lugares in Projeto História. São Paulo: PUC, n. 10, dezembro de 1993.

ORNELAS, Fábio. A esquina do cinema. Documentário realizado para o trabalho de finalização de Pós-Graduação em Vídeo-Jornalismo na PUC-SP, São Paulo, 2012.

RIBEIRO, Renilson Rosa. Nos jardins do tempo: memória e história nas perspectivas de Pierre Nora. PUC-SP, São Paulo, 2009.

ROUANET, Sérgio Paulo. Walter Benjamin: Magia e Técnica, Arte e Política. Ensaios sobre literatura e histeria da cultura. Ed. Brasiliente, São Paulo, 1987.

Sítio da Cinemateca Brasileira: http://www.cinemateca.gov.br/

STEFANI, Eduardo Baider. A geografia dos cinemas no lazer paulistano contemporâneo: redes e territorialidades dos cinemas de arte multiplex. Tese de mestrado, FFLCH-USP, São Paulo, 2003.

STURMN, André Pompéia. Conferência proferida na Casa da Cidade no dia 17/08/2011 no evento Cidade, memória e cinemas de rua: o caso do Cine Belas Arte.

TORRES, Lilian de Lucca. Programa de Paulista: lazer no Bexiga e na avenida Paulista com a rua da Consolação in TORRES, Lilian de Lucca e MAGANANI, José Guilherme. Na Metrópole: textos de antropologia urbana. Edusp, São Paulo, 1996.

VEIGA, Ana Cecília Rocha. A materialidade da dimensão intangível do patrimônio cultural urbano. Teses de mestrado, UFMG, 2005. 